Article

\title{
Martensitic Transformation in Ni-Mn-Sn-Co Heusler Alloys
}

\author{
Alexandre Deltell ${ }^{\dagger}$, Lluisa Escoda ${ }^{\dagger}$, Joan Saurina ${ }^{\dagger}$ and Joan Josep Suñol * \\ Department of Physics, University of Girona, Campus Montilivi s/n, 17071 Girona, Spain; \\ E-Mails: alexandre.deltell@udg.edu (A.D.); 1luisa.escoda@udg.edu (L.E.); \\ joan.saurina@udg.edu (J.S.) \\ $\dagger$ These authors contributed equally to this work. \\ * Author to whom correspondence should be addressed; E-Mail: joanjosep.sunyol@udg.edu; \\ Tel.: +34-972-419-757; Fax: +34-972-418-098.
}

Academic Editor: Kurt R. Ziebeck

Received: 1 March 2015 / Accepted: 24 April 2015 / Published: 28 April 2015

\begin{abstract}
Thermal and structural austenite to martensite reversible transition was studied in melt spun ribbons of $\mathrm{Ni}_{50} \mathrm{Mn}_{40} \mathrm{Sn}_{5} \mathrm{Co} 5, \mathrm{Ni}_{50} \mathrm{Mn}_{37.5} \mathrm{Sn}_{7.5} \mathrm{Co}$ and $\mathrm{Ni}_{50} \mathrm{Mn}_{35} \mathrm{Sn}_{10} \mathrm{Co} 5$ (at. \%) alloys. Analysis of X-ray diffraction patterns confirms that all alloys have martensitic structure at room temperature: four layered orthorhombic $4 \mathrm{O}$ for $\mathrm{Ni}_{50} \mathrm{Mn}_{40} \mathrm{Sn}_{5} \mathrm{Co}$, four layered orthorhombic $4 \mathrm{O}$ and seven-layered monoclinic $14 \mathrm{M}$ for $\mathrm{Ni}_{50} \mathrm{Mn}_{37.5} \mathrm{Sn}_{7.5} \mathrm{Co}_{5}$ and seven-layered monoclinic $14 \mathrm{M}$ for $\mathrm{Ni}_{50} \mathrm{Mn}_{35} \mathrm{Sn}_{5} \mathrm{Co}$. Analysis of differential scanning calorimetry scans shows that higher enthalpy and entropy changes are obtained for alloy $\mathrm{Ni}_{50} \mathrm{Mn}_{37.5} \mathrm{Sn}_{7.5} \mathrm{Co}$, whereas transition temperatures increases as increasing valence electron density.
\end{abstract}

Keywords: magnetic shape memory; martensitic transformation; DSC; XRD; Ni-Mn-Sn-Co

\section{Introduction}

Ferromagnetic shape memory (FSM) alloys are of considerable interest due to their exceptional magnetoelastic properties. Their potential functional properties include: Magnetic superelasticity [1], large inverse magnetocaloric effect [2] and large magneto-resistance change [3]. Most of these effects are ascribed to the existence of a first order martensitic transformation with a strong magneto-structural coupling. Transformation temperatures of shape memory alloys depend on the composition and their 
values spread to a very wide range [4]. These materials are interesting for the development of new magnetically driven actuators, sensors and coolers for magnetic refrigeration [5].

FSM behavior is found in Heusler alloys, which have a generic formula $\mathrm{X}_{2} \mathrm{YZ}$ and are defined as ternary intermetallic systems with L $2{ }_{1}$ crystalline cubic structure. The most extensively studied Heusler alloys are those based on the Ni-Mn-Ga system. However, to overcome some of the problems related with practical applications (such as the high cost of Gallium and the usually low martensitic transformation temperature), Ga-free alloys have been searched and analyzed frequently during the last few decades, specifically with the introduction of In or Sn. Martensitic transformation in ferromagnetic Heusler $\mathrm{Ni}_{50} \mathrm{Mn}_{50-x} \mathrm{Sn}_{x}$ bulk alloys with $10 \leq x \leq 16.5$ was first reported by Sutou et al. [6]. Later, Krenke et al. studied magnetic and magnetocaloric properties and phase transformations in $\mathrm{Ni}_{50} \mathrm{Mn}_{50-x} \mathrm{Sn}_{x}$ alloys with $5 \leq x \leq 25$ [7]. Rapid solidification techniques, such as melt-spinning, are an alternative to obtain these materials (ribbon shape) [8,9].

Another important factor affecting the magnetic behavior of Ni-Mn-Sn and Ni-Mn-Sn-Co systems is the annealing process. Some authors have found different magnetic behavior in melt-spun Ni-Mn-Sn-Co ribbons annealed at temperatures from $973 \mathrm{~K}$ to $1173 \mathrm{~K}[10,11]$.

In our work, we investigate the structural and thermal behavior of three melt-spun alloys of the $\mathrm{Ni}-\mathrm{Mn}-\mathrm{Sn}$-Co system (by modifying $\mathrm{Mn}$ and $\mathrm{Sn}$ atomic \%). These ribbons were not annealed.

\section{Experimental Section}

Polycrystalline Ni-Mn-Sn-Co alloy ingots were prepared by arc melting high purity (99.99\%) elements under argon environment in a water-cooled quartz crucible. The ingots were melted three times to ensure a good homogeneity. Thus, ingots were melt-spun on a rotating copper wheel (Buheler, Lake Bluff, IL, USA) set by controlling process parameters as: Linear wheel speed $\left(48 \mathrm{~ms}^{-1}\right)$, atmosphere (argon, $400 \mathrm{mbar}$ ), injection overpressure (500 mbar) and distance between wheel and injection quartz crucible $(3 \mathrm{~mm})$. The as-spun ribbon samples (Alfa Aesar, Heysham, UK) obtained were: $\mathrm{Ni}_{50} \mathrm{Mn}_{40} \mathrm{Sn}_{5} \mathrm{Co} 5, \mathrm{Ni}_{50} \mathrm{Mn}_{37.5} \mathrm{Sn}_{7.5} \mathrm{Co} 5$ and $\mathrm{Ni}_{50} \mathrm{Mn}_{35} \mathrm{Sn}_{10} \mathrm{Co} 5$ (at. \%). The main difference among these alloys is the partial substitution of $\mathrm{Mn}$ by $\mathrm{Sn}$ whereas the content of $\mathrm{Co}$ and $\mathrm{Mn}$ is constant.

Thermal and structural analyses were performed by applying several techniques. Scanning electron microscopy (SEM) investigations were carried out using a Zeiss DSM 960A microscope (Zeiss, Jena, Germany) operating at $30 \mathrm{kV}$ and linked to an energy dispersive X-ray spectrometer (EDX; Zeiss, Jena, Germany). X-ray diffraction (XRD) analyses were performed at room temperature with a Siemens D500 X-ray powder diffractometer (Bruker, Bullerica, MA, USA) using $\mathrm{Cu}-\mathrm{K}_{\alpha}$ radiation. Thermal analyses were performed by differential scanning calorimetry (DSC) using a DSC822e calorimeter of Mettler-Toledo (Mettler Toledo, Columbus, $\mathrm{OH}$, USA) working at a heating/cooling rate of $10 \mathrm{~K} / \mathrm{min}$ under argon atmosphere.

\section{Results and Discussion}

Heusler alloys produced by melt spinning show a typical columnar structure in the fracture cross section. Figure 1 shows the micrographs of the fracture section of alloys $\mathrm{Ni}_{50} \mathrm{Mn}_{40} \mathrm{Sn}_{5} \mathrm{Co}$, $\mathrm{Ni}_{50} \mathrm{Mn}_{37.5} \mathrm{Sn} 7.5 \mathrm{Co} 5$ and $\mathrm{Ni}_{50} \mathrm{Mn}_{35} \mathrm{Sn}_{10} \mathrm{Co}$, labeled as A, B and $\mathrm{C}$ respectively. All ribbon flakes have a similar morphology which consists of: fully crystalline and granular columnar type microstructure. 
This is a sign of the quick crystallization and fast growth kinetics of the samples. This suggests that the heat removal during rapid solidification process induces the directional growth of the crystalline phase. The ribbons' width is also similar (between 12 and $15 \mu \mathrm{m}$ ).

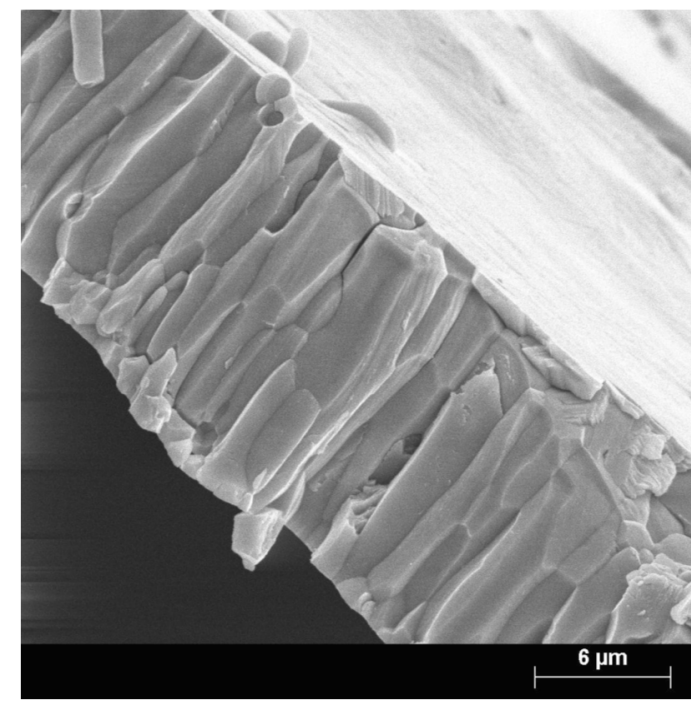

(A)

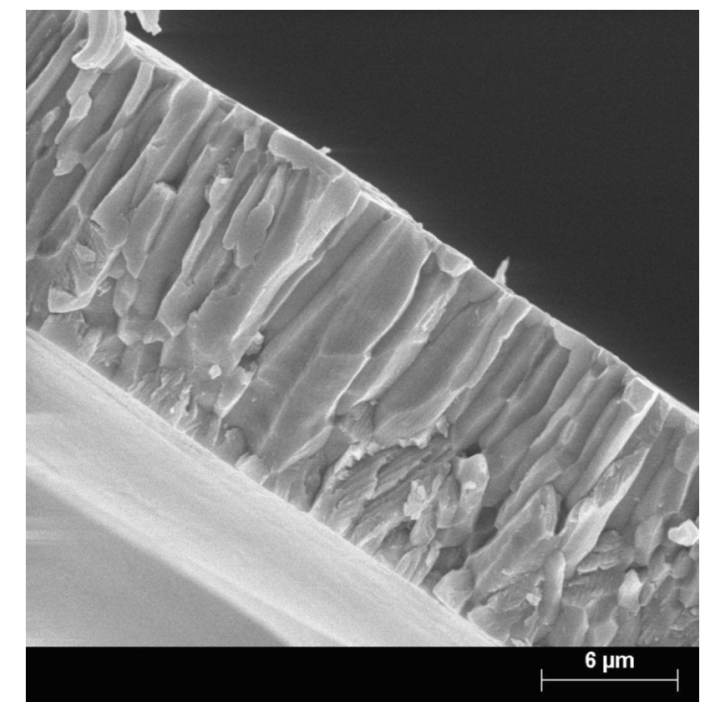

(B)

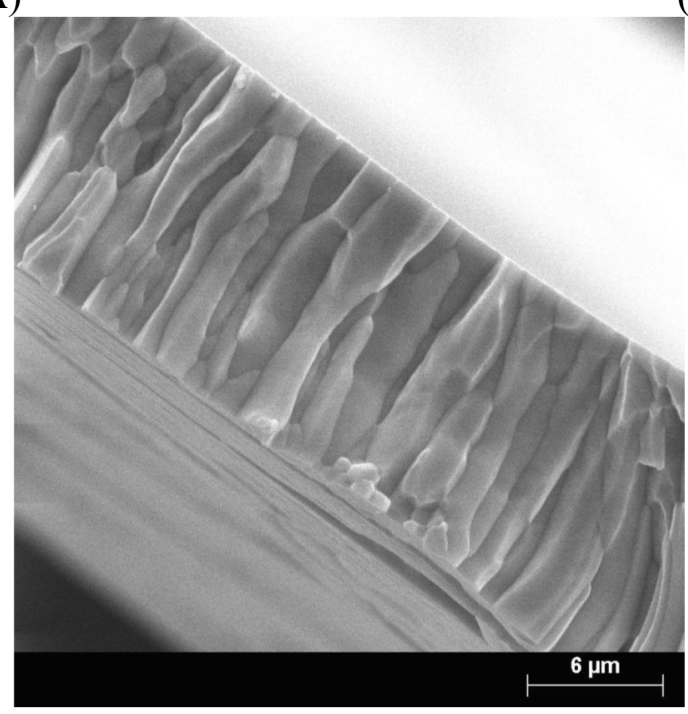

(C)

Figure 1. SEM micrographs of the cross section of alloys $\mathrm{Ni}_{50} \mathrm{Mn}_{40} \mathrm{Sn}_{5} \mathrm{Co}$, $\mathrm{Ni}_{50} \mathrm{Mn}_{37.5} \mathrm{Sn}_{7.5} \mathrm{Co} 5$ and $\mathrm{Ni}_{50} \mathrm{Mn}_{35} \mathrm{Sn}_{10} \mathrm{Co}_{05}$, labeled as $(\mathbf{A}),(\mathbf{B})$ and $(\mathbf{C})$ inside the figure.

Crystalline structures at room temperature were determined by analyzing X-Ray diffraction patterns of the three samples (see Figures 2-4 for alloys $\mathrm{Ni}_{50} \mathrm{Mn}_{40} \mathrm{Sn}_{5} \mathrm{Co}_{5} ; \mathrm{Ni}_{50} \mathrm{Mn}_{37.5} \mathrm{Sn}_{7.5} \mathrm{Co}_{5}$ and $\mathrm{Ni}_{50} \mathrm{Mn}_{35} \mathrm{Sn}_{10} \mathrm{Co} 5$ respectively). X-ray diffraction analysis begins with in an indexation based on the identification proposed by other authors [7,12,13]. The lattice parameters were first calculated minimizing the global interplanar spacing $\left(\mathrm{d}_{h k l}\right)$ error; defined as the difference between the values calculated from the Bragg equation to every identified peak of the XRD pattern compared to the crystal system geometry equation.

It is found that, at room temperature, all alloys have martensitic structure. This martensitic structure is confirmed to be four layered orthorhombic $4 \mathrm{O}$ for $\mathrm{Ni}_{50} \mathrm{Mn}_{40} \mathrm{Sn}_{5} \mathrm{Co}$, four layered orthorhombic $4 \mathrm{O}$ 
and seven-layered monoclinic $14 \mathrm{M}$ for $\mathrm{Ni}_{50} \mathrm{Mn}_{37.5} \mathrm{Sn}_{7.5} \mathrm{Co}$ and seven-layered monoclinic $14 \mathrm{M}$ for $\mathrm{Ni}_{50} \mathrm{Mn}_{35} \mathrm{Sn}_{10} \mathrm{Co}$. Lattice parameters are given in Table 1 (for $\mathrm{Ni}_{50} \mathrm{Mn}_{37.5} \mathrm{Sn}_{7.5} \mathrm{Co}$ alloy only parameters from the main phase, $4 \mathrm{O}$, are given).

In our work it is found that substituting Mn with Sn favors to the formation of the modulated 14M monoclinic structure. Thus, the martensitic structure is $4 \mathrm{O}$ in samples with higher $\mathrm{Mn} / \mathrm{Sn}$ ratio and $14 \mathrm{M}$ in samples with lower $\mathrm{Mn} / \mathrm{Sn}$ ratio. Opposite behavior was found in Ni-Mn-Sn bulk alloys without Co [14]. Thus, the Co addition probably influences what kind of martensitic phase is more stable. In Ni-Mn-Sn-Co ribbons, it was found that the addition of Co favors the evolution of the martensitic crystalline structure from a four-layered orthorhombic (4O) to a five-layered orthorhombic (10M) and finally to a seven-layered monoclinic (14M) [15]. Thus, the addition of Co favors the formation of the 14M structure. This effect was not found in our alloys, probably because Co content is constant. Furthermore, it has been also found that the martensitic crystal structure changes from $14 \mathrm{M}$ in the bulk alloy to $4 \mathrm{O}$ in the melt spun ribbons due to the high oriented microstructure [16]. In summary, the differences between our results and results from bibliography can be influenced by the combination of these three factors: Co constant content, $\mathrm{Mn} / \mathrm{Sn}$ ratio and high oriented ribbons microstructure. More than three alloys are needed to check the influence of these parameters.

Table 1. Crystalline structure and lattice parameters of $\mathrm{Ni}_{50} \mathrm{Mn}_{40} \mathrm{Sn}_{5} \mathrm{Co}$, $\mathrm{Ni}_{50} \mathrm{Mn}_{37.5} \mathrm{Sn}_{7.5} \mathrm{Co} 5$ and $\mathrm{Ni}_{50} \mathrm{Mn}_{35} \mathrm{Sn}_{10} \mathrm{Co} 5$. The angle of the monoclinic $14 \mathrm{M}$ structure is $95.56^{\circ}$, (for $\mathrm{Ni}_{50} \mathrm{Mn}_{37.5} \mathrm{Sn}_{7.5} \mathrm{Co} 5$ alloy only parameters from the main phase are given).

\begin{tabular}{ccccc}
\hline \multirow{2}{*}{ Alloy } & $\begin{array}{c}\text { Crystalline } \\
\text { structure }\end{array}$ & $\begin{array}{c}\text { Lattice Parameter } \\
\boldsymbol{a} / \mathbf{n m}\end{array}$ & $\begin{array}{c}\text { Lattice Parameter } \\
\boldsymbol{b} / \mathbf{n m}\end{array}$ & $\begin{array}{c}\text { Lattice Parameter } \\
\boldsymbol{c} / \mathbf{n m}\end{array}$ \\
\hline $\mathrm{Ni}_{50} \mathrm{Mn}_{40} \mathrm{Sn}_{5} \mathrm{Co}_{5}$ & $4 \mathrm{O}$ & 0.8828 & 0.5817 & 0.4274 \\
$\mathrm{Ni}_{50} \mathrm{Mn}_{37.5} \mathrm{Sn}_{7.5} \mathrm{Co}_{5}$ & $4 \mathrm{O}$ & 0.8922 & 0.5892 & 0.4281 \\
$\mathrm{Ni}_{50} \mathrm{Mn}_{35} \mathrm{Sn}_{10} \mathrm{Co}_{5}$ & $14 \mathrm{M}$ & 0.4298 & 0.5612 & 2.9441 \\
\hline
\end{tabular}

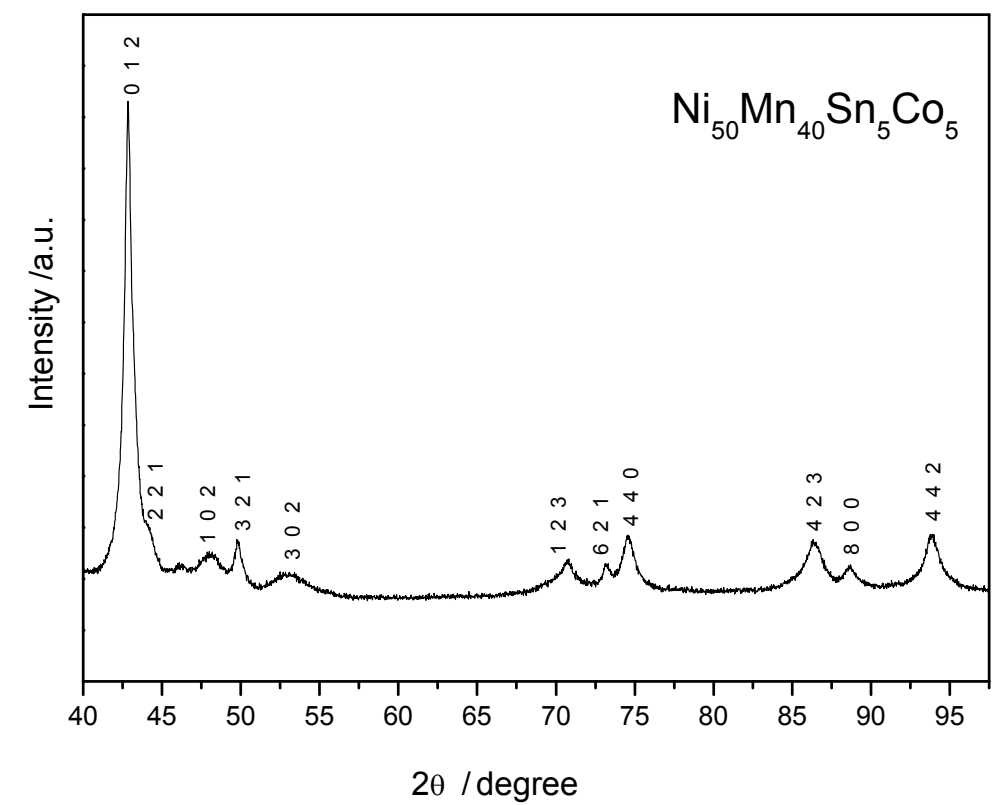

Figure 2. X-ray diffraction (XRD) pattern, at room temperature, of $\mathrm{Ni}_{50} \mathrm{Mn}_{40} \mathrm{Sn}_{5} \mathrm{Co}$ ribbon. The indexation corresponds to a four-layered 40 orthorhombic structure. 


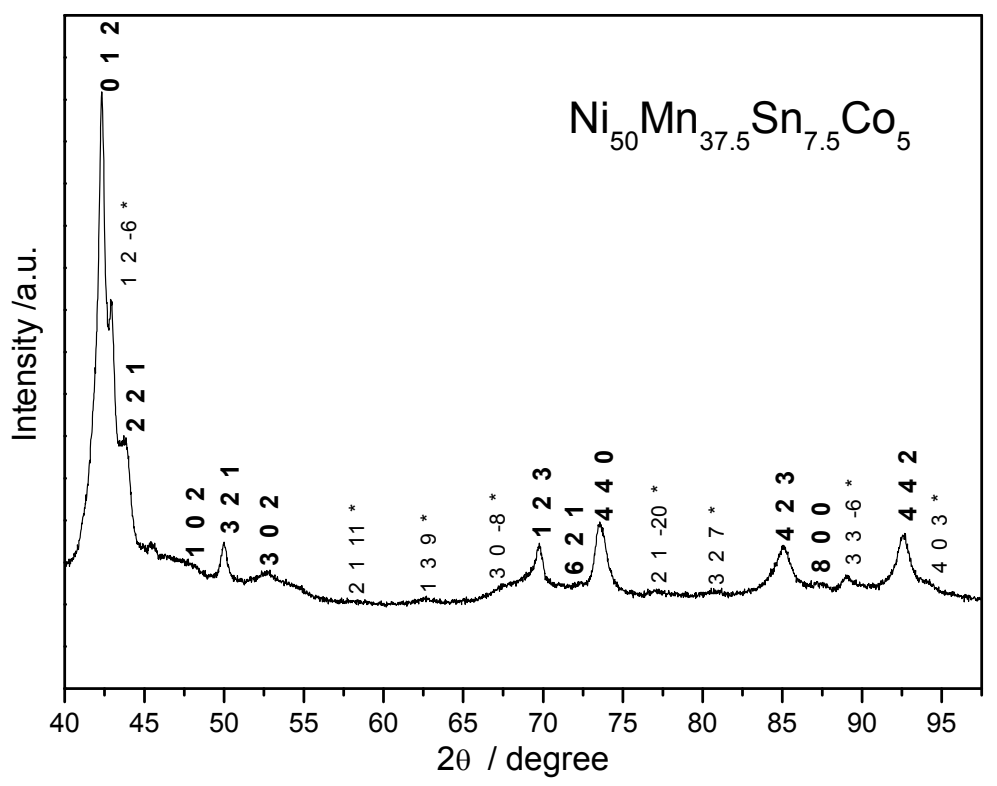

Figure 3. XRD pattern, at room temperature, of $\mathrm{Ni}_{50} \mathrm{Mn}_{37.5} \mathrm{Sn}_{7.5} \mathrm{Co} 5$ ribbon. The indexation of the main phase corresponds to a four-layered 40 orthorhombic structure, whereas peaks marked with * correspond to a modulated monoclinic seven-layered 14M structure.

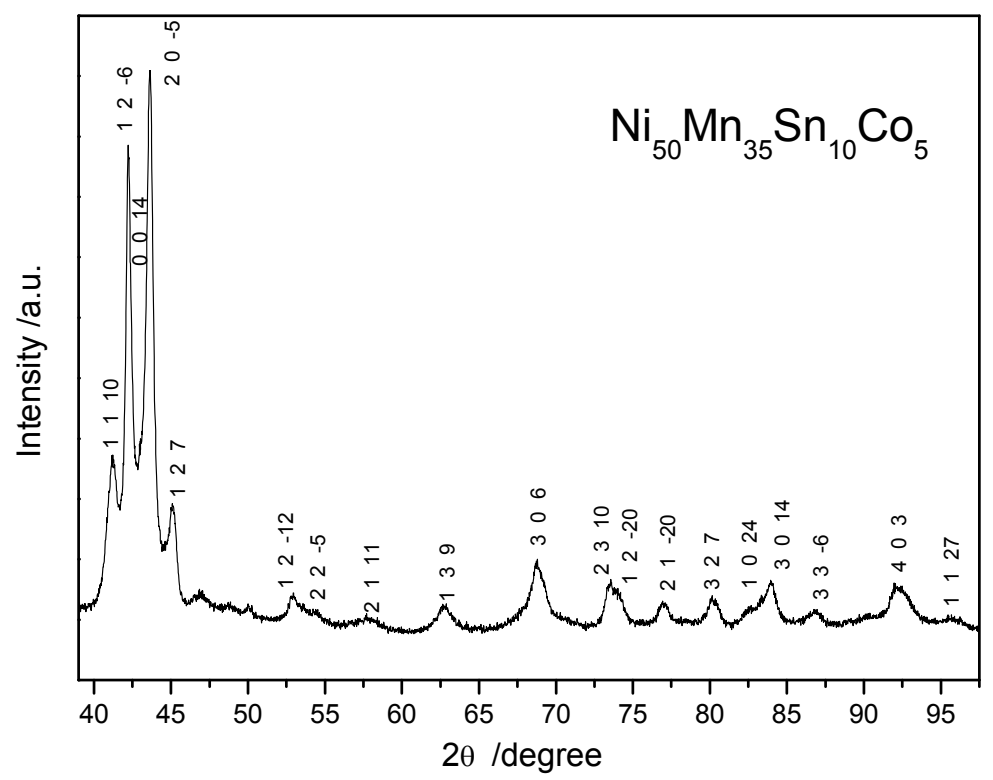

Figure 4. XRD pattern, at room temperature, of $\mathrm{Ni}_{50} \mathrm{Mn}_{35} \mathrm{Sn}_{10} \mathrm{Co} 5$ ribbon. The indexation of the main phase correspond to a modulated monoclinic seven-layered $14 \mathrm{M}$ structure.

At room temperature, XRD show that all samples have a martensitic phase. Thus, the occurrence of the martensitic transformation should be checked by DSC heating from room temperature (see Figures 5-7). The reversible austenite - martensite transformation was found in all samples. The absence of any secondary thermal process suggests that the produced ribbons are homogeneous. From DSC analysis characteristic transformation temperatures are determined. Start and finishing martensite and austenite transformation temperatures are referred as $M_{s}, M_{f}$ and $A_{s}, A_{f}$ respectively. 


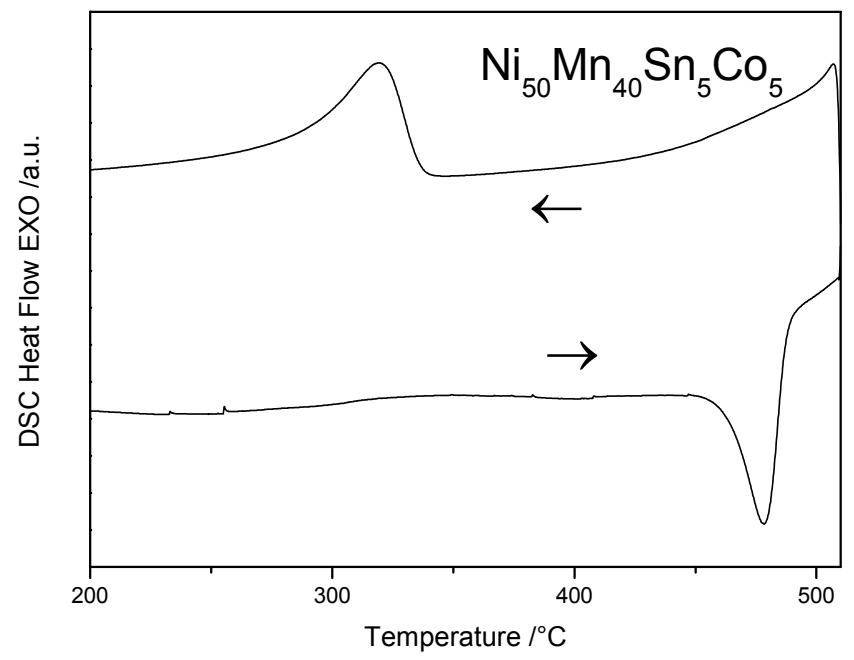

Figure 5. Differential scanning calorimetry (DSC) cyclic scan of alloy Ni50 $\mathrm{Mn}_{40} \mathrm{Sn}_{5} \mathrm{Co}$.

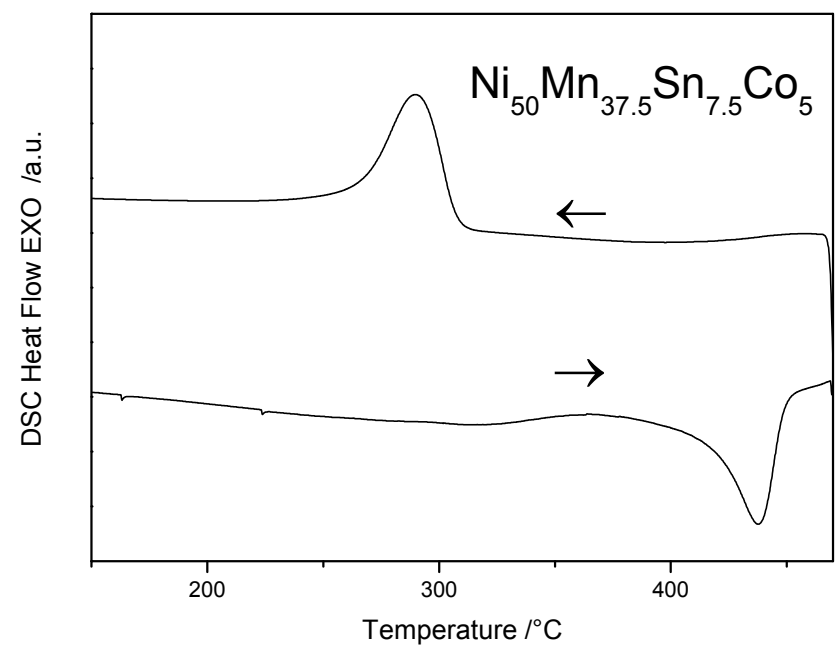

Figure 6. DSC cyclic scan of alloy Ni50Mn37.5Sn7.5 Co5.

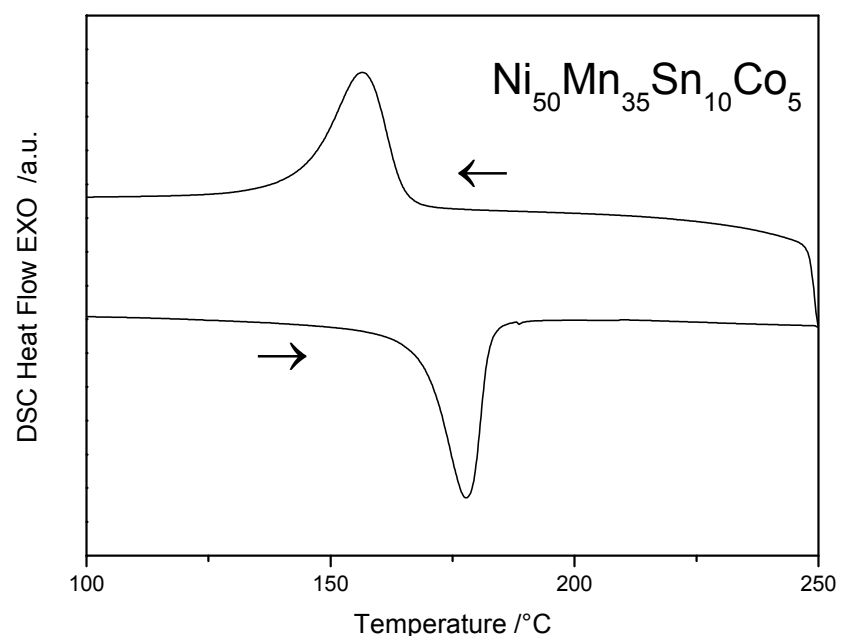

Figure 7. DSC cyclic scan of alloy $\mathrm{Ni}_{50} \mathrm{Mn}_{35} \mathrm{Sn}_{10} \mathrm{Co}$.

The martensitic transformation of Ni-Mn-Sn alloys is athermal in nature although a time-depending effect is observed through calorimetry interrupted measurements [17]. The thermal hysteresis, $\Delta T$, exists 
due to the increase of the elastic and the surface energies during the martensitic formation. Thus, the nucleation of the martensite implies supercooling.

The equilibrium transformation temperature between martensite and austenite, $T_{\mathrm{o}}$, is usually defined as $\left(M_{s}+A_{f}\right) / 2$. All the characteristic temperatures are given in Table 2 .

Table 2. Characteristic temperatures and thermal hysteresis as determined from DSC cyclic scans: $\mathrm{Ni}_{50} \mathrm{Mn}_{40} \mathrm{Sn}_{5} \mathrm{Co}$, $\mathrm{Ni}_{50} \mathrm{Mn}_{37.5} \mathrm{Sn}_{7.5} \mathrm{Co} 5$ and $\mathrm{Ni}_{50} \mathrm{Mn}_{35} \mathrm{Sn}_{10} \mathrm{Co5}$. Start and finishing martensite and austenite formation temperatures are referred as $M_{s}, M_{f}$ and $A_{s}, A_{f}$ respectively. Thermal hysteresis, $\Delta T$, and equilibrium transformation temperature between martensite and austenite, $T_{\mathrm{o}}$.

\begin{tabular}{ccccccc}
\hline Alloy & $\boldsymbol{M}_{\boldsymbol{s}} / \mathbf{K}$ & $\boldsymbol{M}_{\boldsymbol{f}} / \mathbf{K}$ & $\boldsymbol{A}_{\boldsymbol{s}} / \mathbf{K}$ & $\boldsymbol{A}_{\boldsymbol{f}} / \mathbf{K}$ & $\boldsymbol{T}_{\mathbf{0}} / \mathbf{K}$ & $\boldsymbol{\Delta} \boldsymbol{T} / \mathbf{K}$ \\
\hline $\mathrm{Ni}_{50} \mathrm{Mn}_{40} \mathrm{Sn}_{5} \mathrm{Co}_{5}$ & 616.8 & 477.2 & 723.8 & 764.8 & 690.8 & 158.1 \\
$\mathrm{Ni}_{50} \mathrm{Mn}_{37.5} \mathrm{Sn}_{7.5} \mathrm{Co}_{5}$ & 593.3 & 478.0 & 677.7 & 727.8 & 660.6 & 146.7 \\
$\mathrm{Ni}_{50} \mathrm{Mn}_{35} \mathrm{Sn}_{10} \mathrm{Co}_{5}$ & 453.2 & 398.2 & 432.1 & 474.9 & 464.1 & 25.5 \\
\hline
\end{tabular}

It is found that substituting $\mathrm{Mn}$ by $\mathrm{Sn}$ favors the decrease of the phase transition temperatures. Opposite effect was found in bulk Ni-Mn-Sn alloys without Co [14]. Similarly, the addition of Co in $\mathrm{Ni}-\mathrm{Mn}-\mathrm{Sn}$ melt-spun alloys increases martensitic transformation temperatures [16]. When doping the alloys, it is important which atom is substituted. In Ni-Mn-Sn-Fe bulk alloys the partial substitution of $\mathrm{Mn}$ by Fe causes a diminution of the transition temperatures [12]. The same effect is observed in our alloys by substituting Mn by Co. Likewise, the partial substitution of Mn does not induce a general trend in the temperatures [13] whereas Co addition in Ni-Mn-Ga alloys increases the temperatures of the martensitic transformation [18]. Furthermore, annealing also modifies transformation temperatures and thermal hysteresis [10]. Thus, so many parameters affect structural transformation to assure which parameter determines the behavior of our samples.

Changes in enthalpy, $\Delta H$, and entropy, $\Delta S$, during structural transformation are calculated from the area of the DSC peaks. Figure 8 shows its evolution as a function of the average valence electron density $(e / a)$. The shift on the characteristic temperatures and thermodynamic parameters is related to $e / a$ [19]. The valence electrons per atom are $10\left(3 d^{8} 4 s^{2}\right)$ for Ni, $9\left(3 d^{7} 4 s^{2}\right)$ for Co, $7\left(3 d^{5} 4 s^{2}\right)$ for Mn and $4\left(5 s^{2} 5 p^{2}\right)$ for Sn, respectively.

Energy-dispersive X-ray spectroscopy microanalysis has been used to obtain the exact composition of every sample and to calculate $e / a$ parameter. EDX elemental composition and average valence electron density are presented in Table 3.

Higher values of enthalpy and entropy are those of $\mathrm{Ni}_{50} \mathrm{Mn}_{37.5} \mathrm{Sn}_{7.5} \mathrm{Co} 5$ alloy, probably due to the coexistence of two crystalline phases.

One of the most typical ferromagnetic shape memory alloy phase diagram is the graphical representation of the martensitic start temperature as a function of the $Z$ element content or as a function of the average valence electron density. In Figure 9 we represent $M_{s}$ temperatures obtained in this work (symbols) and those obtained assuming linear relation in Ni-Mn-Sn bulk alloys [20]. 


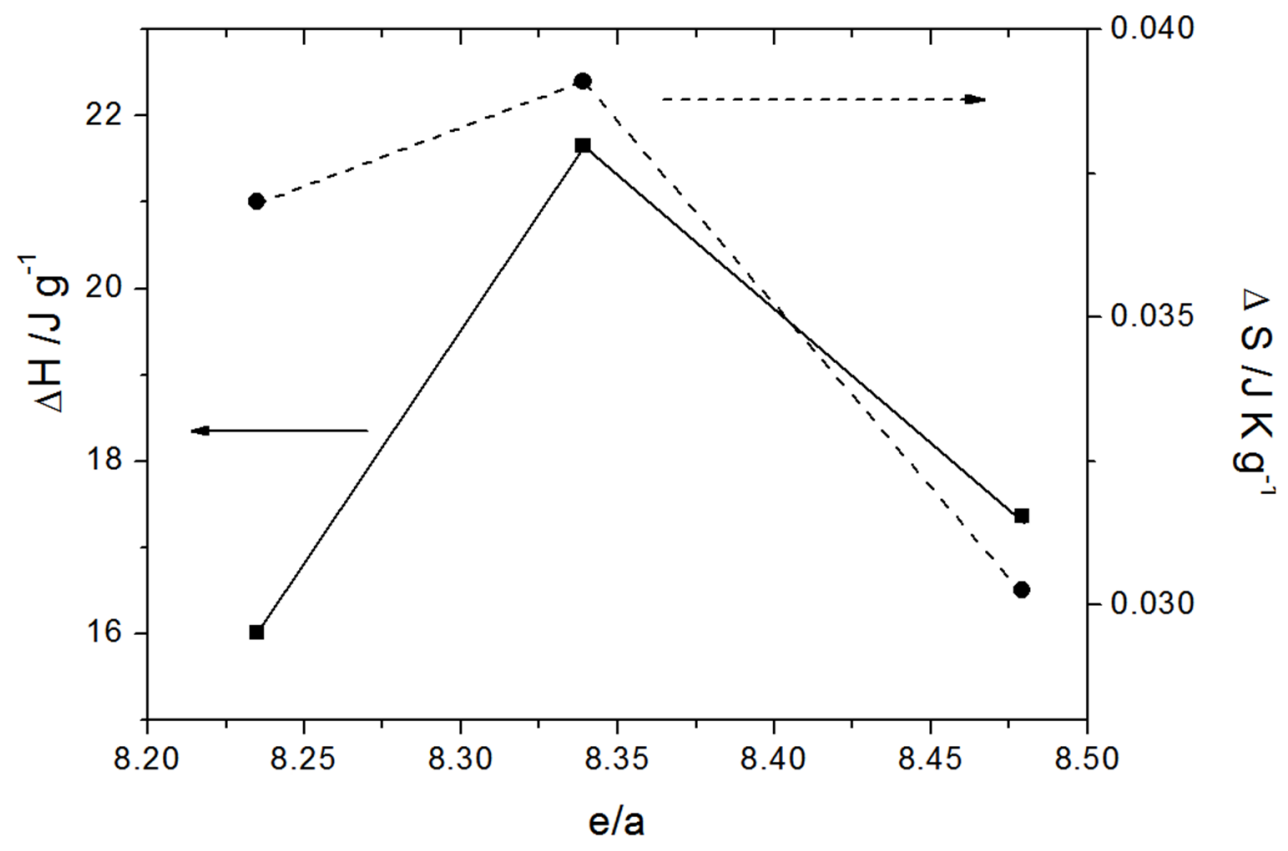

Figure 8. Enthalpy $(\Delta H)$ and entropy $(\Delta S)$ changes as a function of average valence electron density. Symbols: Enthalpy (square), entropy (circle). Error: $<3 \%$.

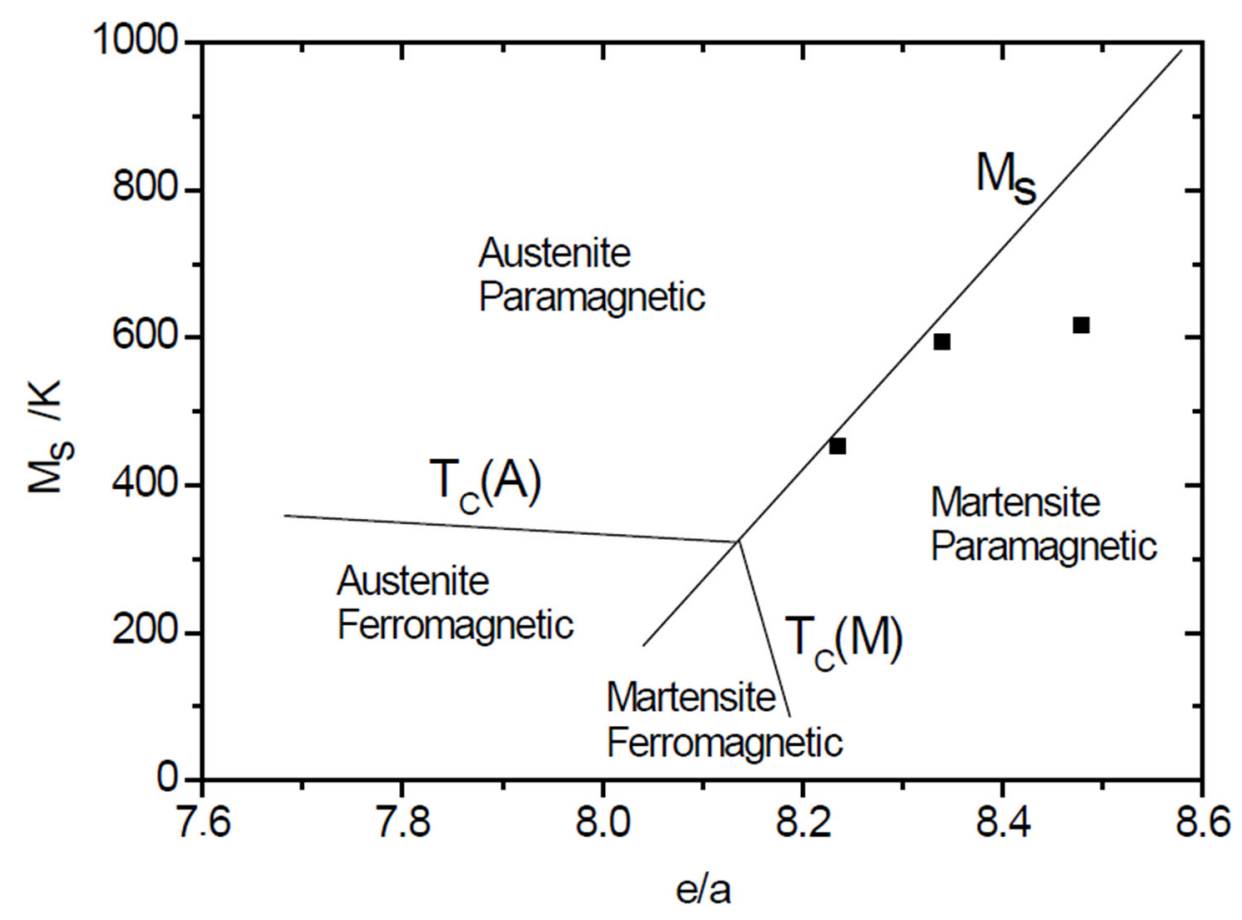

Figure 9. Martensitic start temperature versus average valence electron density. Lines correspond to bulk alloys [20] whereas square symbols correspond to our samples.

Table 3. Energy dispersive X-ray spectrometer (EDX) compositions of $\mathrm{Ni}_{50} \mathrm{Mn}_{40} \mathrm{Sn}_{5} \mathrm{Co}$, $\mathrm{Ni}_{50} \mathrm{Mn}_{37.5} \mathrm{Sn}_{7.5} \mathrm{Co} 5$ and $\mathrm{Ni}_{50} \mathrm{Mn}_{35} \mathrm{Sn}_{5} \mathrm{Co}_{5}$, and average valence electron density.

\begin{tabular}{cccccc}
\hline Alloy & Ni & Mn & Sn & Co & $\boldsymbol{e} / \boldsymbol{a}$ \\
\hline $\mathrm{Ni}_{50} \mathrm{Mn}_{40} \mathrm{Sn}_{5} \mathrm{Co}_{5}$ & 50.7 & 39.12 & 4.91 & 5.27 & 8.479 \\
$\mathrm{Ni}_{50} \mathrm{Mn}_{37.5} \mathrm{Sn}_{7.5} \mathrm{Co}_{5}$ & 49.8 & 35.99 & 8.78 & 5.44 & 8.339 \\
$\mathrm{Ni}_{50} \mathrm{Mn}_{35} \mathrm{Sn}_{10} \mathrm{Co}_{5}$ & 49.35 & 34.51 & 11.37 & 4.77 & 8.235 \\
\hline
\end{tabular}


Our results show a diminution of the transformation temperatures. The main difference is for alloy $\mathrm{Ni}_{50} \mathrm{Mn}_{40} \mathrm{Sn}_{5} \mathrm{Co}$. In the literature it was found that the martensitic transformation, in Heusler Ni-Mn-Sn melt spun ribbons, occurs at lower temperatures than those compared to bulk alloys [15]. Moreover, a change of the martensitic crystalline structure from $14 \mathrm{M}$ to $4 \mathrm{O}$ takes place with the decrease of the martensitic transition temperature. It is proposed that the internal stress was induced due to the highly-oriented microstructure, which leads to the decrease of the transition temperature because of a refined martensite plate and the formation of dense martensitic variants with different orientations. These results were supported by high resolution transmission electron microscopy (HRTEM). Furthermore, it was also found that the partial substitution of $\mathrm{Ni}$ by Co shifts the martensitic transformation to lower temperatures in Ni-Mn-Sn-Co bulk alloys [21]. If our alloys have the same trend that bulk alloys (Figure 9), it is not clear the occurrence of the magnetic transformation.

\section{Conclusions}

Melt-spun ribbon of three alloys of the Ni-Co-Mn-Sn system has been produced: Ni50 $\mathrm{Mn}_{40} \mathrm{Sn}_{5} \mathrm{Co}$, $\mathrm{Ni}_{50} \mathrm{Mn}_{37.5} \mathrm{Sn}_{7.5} \mathrm{Co} 5$ and $\mathrm{Ni}_{50} \mathrm{Mn}_{35} \mathrm{Sn}_{10} \mathrm{Co}$. The austenite to martensite reversible transformation was found in all samples. Transformation temperatures increase as $\mathrm{Mn} / \mathrm{Sn}$ ratio increases.

Martensitic structure is four-layered orthorhombic $4 \mathrm{O}$ in samples with higher $\mathrm{Mn} / \mathrm{Sn}$ ratio and monoclinic modulated seven-layered $14 \mathrm{M}$ in samples with lower $\mathrm{Mn} / \mathrm{Sn}$ ratio. These results differ from other obtained in the bibliography. Probably, these differences are caused by the combination of three factors: constant Co content, $\mathrm{Mn} / \mathrm{Sn}$ ratio and high oriented ribbons microstructure. Furthermore, substituting Mn by Sn favors to the decrease of the austenite-martensite reversible transition temperatures.

\section{Acknowledgments}

This research was supported by the projects MAT2013-47231-C2-2-P and 2014SGR1180.

\section{Author Contributions}

Alexandre Deltell is a doctorate student. The thesis works are supervised by Joan Josep Suñol and Lluisa Escoda. Joan Saurina supports DSC analysis.

\section{Conflicts of Interest}

The authors declare no conflict of interest.

\section{References}

1. Krenke, T.; Duman, E.; Acet, M.; Wasserman, E.F.; Moya, X.; Mañosa, L.; Planes, A.; Suard, E.; Ouaddiaf, B. Magnetic superelasticity and reverse magnetocaloric effect in Ni-Mn-In. Phys. Rev. B 2007, 75, 104414.

2. Caballero-Flores, R.; González-Legarreta, L.; Rosa, W.O.; Sánche, T.; Prida, V.M.; Escoda, L.; Suñol, J.J.; Batdalov, A.B.; Aliev, A.M.; Koledov, V.V.; et al. Magnetocaloric effect, magnetostructural and magnetic phase transformations in $\mathrm{Ni}_{50.3} \mathrm{Mn}_{36.5} \mathrm{Sn}_{13.2}$ Heusler alloy ribbons. J. Alloys Compd. 2015, 629, 332-342. 
3. Barandiarán, J.M.; Chernenko, V.A.; Lazpita, P.; Gutiérrez, J.; Feuchtwanger, J. Effect of martensitic transformation and magnetic field on transport properties of Ni-Mn-Ga and Ni-Fe-Ga Heusler alloys. Phys. Rev. B 2009, 80, 104404.

4. Coll, R.; Escoda, L.; Saurina, J.; Sánchez-Llamazares, J.L.; Hernando, B.; Suñol, J.J. Martensitic transformation in Mn-Ni-Sn Heusler alloys. J. Therm. Anal. Calorim. 2010, 99, 905-909.

5. Marioni, M.A.; O’Handley, R.C.; Allen, S.M.; Hall, S.R.; Paul, D.I.; Richard, M.L.; Feuchtwanger, J.; Peterson, B.W.; Chambers, J.M.; Techapiesancharoenkij, R. The ferromagnetic shape-memory effect in Ni-Mn-Ga. J. Magn. Magn. Mater. 2005, 290, 35-41.

6. Sutou, Y.; Imano, Y.; Koeda, N.; Omori, T.; Kainuma, R.; Ishida, K.; Oikawa, K. Magnetic and martensitic transformations of $\operatorname{BiMn} X(X=\mathrm{In}, \mathrm{Sn}, \mathrm{Sb})$ ferromagnetic shape memory alloys. Appl. Phys. Lett. 2004, 85, 4358.

7. Krenke, T.; Duman, E.; Acet, M.; Wassermann, E.F.; Moya, X.; Mañosa, L.; Planes, A. Inverse magnetocaloric effect in ferromagnetic Ni-Mn-Sn alloys. Nat. Mater. 2005, 4, 450-454.

8. Hernando, B.; Sánchez-Llamazares, J.L.; Santos, J.D.; Escoda, L.; Suñol, J.J.; Varga, R.; Baldomir, D.; Serantes, D. Thermal and magnetic field-induced mrtensite-austenite transition in $\mathrm{Ni}_{50.3} \mathrm{Mn}_{35.3} \mathrm{Sn}_{14.4}$ ribbons. Appl. Phys. Lett. 2008, 92, 042504.

9. Santos, J.D.; Sánhez, T.; Álvarez, P.; Sánchez, M.L.; Sánchez-Llamazares, J.L.; Hernando, J.; Escoda, L.; Suñol, J.J.; Varga, R. Microstructure and magnetic properties of $\mathrm{Ni}_{50} \mathrm{Mn}_{37} \mathrm{Sn}_{13}$ Heusler alloy ribbons. J. Appl. Phys. 2008, 103, 07B326.

10. Chen, F.; Liu, W.L.; Shi, Y.G.; Müllner, P. Influence of annealing on martensitic transformation and magnetic entropy change in Ni-Co-Mn-Sn magnetic shape memory alloy ribbon. J. Magn. Magn. Mater. 2015, 377, 137-141.

11. Ma, S.C.; Cao, Q.Q.; Xuan, H.C.; Zhang, C.L.; Shen, L.J.; Wang, D.H.; Du, Y.W. Magnetic and magnetocaloric properties in melt-spun and annealed Ni-Mn-Co-Sn ribbons. J. Alloys Compd. 2011, 509, 1111-1114.

12. Fukushima, K.; Sano, K.; Kanomata, T.; Nishihara, H.; Furutani, Y.; Shishido, T.; Ito, W.; Umetsu, R.Y.; Kainuma, R.; Oikawa, K.; et al. Phase diagram of Fe-substituted Ni-Mn-Sn shape memory alloys. Scr. Mater. 2009, 61, 813-816.

13. Kanomata, T.; Umetsu, R.Y.; Ohtsuki, K.; Shoji, T.; Endo, K.; Fukushima, K.; Nishihara, H.; Ito, W.; Adachi, Y.; Miura, T.; et al. Magnetic phase diagram of Ni2 $\mathrm{Mn}_{1.44-x} \mathrm{Cu}_{x} \mathrm{Sn} 0.56$ shape memory alloys. J. Alloys Compd. 2014, 590, 221-226.

14. Zheng, H.; Wang, W.; Xue, S.; Zhai, Q.; Frenzel, J.; Luo, Z. Composition-dependent crystal structure and martensitic transformation in Heusler Ni-Mn-Sn alloys. Acta Mater. 2013, 61, 4648-4656.

15. Zheng, H.; Wu, W.; Yu, J.; Zhai, Q.; Luo, Z. Martensitic transformations in melt-spun Heusler Ni-Mn-Sn-Co ribbons. J. Mater. Res. 2014, 29, 880-886.

16. Wang, W.; Yu, J.; Luo, Z.; Zheng, H. Origin of retarded martensite transformation in Heusler Ni-Mn-Sn melt-spun ribbons. Intermetallics 2013, 42, 126-129.

17. Zheng, H.; Wang, W.; Wu, D.; Xue, S.; Zhai, Q.; Frenzel, J.; Luo, Z. Athermal nature of the martensitic transformation in Heusler alloy Ni-Mn-Sn. Intermetallics 2013, 36, 90-95.

18. Kanomata, T.; Nunoki, S.; Endo, K.; Kataoka, M.; Nishihara, H.; Khovaylo, V.V.; Umetsu, R.Y.; Shishido, T.; Nagasako, M.; Kainuma, R.; et al. Phase diagram of the ferromagnetic shape memory alloys $\mathrm{Ni}_{2} \mathrm{MnGa}_{1-x} \mathrm{Co}_{x}$. Phys. Rev. B 2012, 85, 134421. 
19. Chernenko, V.A. Composition instability of beta-phase in Ni-Mn-Ga alloys. Scr. Mater. 1999, 40, 523-527.

20. Krenke, T.; Acet, M.; Wassermann, E.F.; Moya, X.; Mañosa, L.; Planes, A. Martensitic transitions and the nature of ferromagnetism in the austenitic and martensitic states of Ni-Mn-Sn alloys. Phys. Rev. B 2005, 72, 014412.

21. Jing, C.; Li, Z.; Zhang, H.L.; Chen, J.P.; Qiao, Y.F.; Cao, S.X.; Zhang, J.C. Martensitic transition and inverse magnetocaloric effect in Co doping Ni-Mn-Sn Heusler alloy. Eur. Phys. J. B 2009, 67, 193-196.

(C) 2015 by the authors; licensee MDPI, Basel, Switzerland. This article is an open access article distributed under the terms and conditions of the Creative Commons Attribution license (http://creativecommons.org/licenses/by/4.0/). 